\title{
SGLT2 Inhibitors as Add-On Therapy to Metformin for People with Type 2 Diabetes: A Review of Placebo-Controlled Trials in Asian versus Non-Asian Patients
}

This article was published in the following Dove Press journal:

Diabetes, Metabolic Syndrome and Obesity: Targets and Therapy

\author{
André J Scheen (1D ${ }^{1,2}$ \\ 'Diabetes, Nutrition and Metabolic \\ Disorders, Department of Medicine, \\ CHU Liège, Liège University, Liège, \\ Belgium; ${ }^{2}$ Clinical Pharmacology Unit, \\ $\mathrm{CHU}$ Liège, Center for Interdisciplinary \\ Research on Medicines (CIRM), Liège \\ University, Liège, Belgium
}

\begin{abstract}
Metformin remains the first pharmacological choice for treating hyperglycemia in type 2 diabetes (T2DM) in most international guidelines. Sodium-glucose cotransporter type 2 inhibitors (SGLT2is) are increasingly used as add-on therapy. T2DM pathophysiology is different in Asian and non-Asian (mainly Caucasian) patients. The aim of this systematic review is to compare the efficacy of SGLT2is vs placebo added to metformin in randomized controlled trials (RCTs: range 12-52 weeks) in Asian versus non-Asian patients with T2DM. The primary endpoint is the reduction in glycated hemoglobin (HbA1c) from baseline and key secondary endpoints are reductions in fasting plasma glucose (FPG), body weight (BW) and systolic blood pressure (SBP). Systematic literature search collected 7 RCTs (3 with 2 doses) in Asian patients (10 analyses, $n=1164$, iSGLT2: canagliflozin, dapagliflozin, ertugliflozin, ipragliflozin, tofogliflozin)) and 10 RCTs (6 with two doses) in non-Asian patients (16 analyses, $n=2482$, iSGLT2: canagliflozin, dapagliflozin, empagliflozin, ertugliflozin, ipragliflozin). Baseline values of $\mathrm{HbA1c}(7.98 \pm 0.19$ vs $7.89 \pm 0.27 \%)$, FPG ( $8.80 \pm 0.46$ vs $9.11 \pm 0.49$ $\mathrm{mmol} / \mathrm{l})$ and SBP $(128.4 \pm 1.6$ vs $130.2 \pm 3.1 \mathrm{mmHg})$ were not significantly different in Asian vs non-Asian patients, but BW was lower in Asian patients $(71.6 \pm 4.8$ vs $88.0 \pm 2.5 \mathrm{~kg}$, $\mathrm{p}<0.001$ ). The placebo-adjusted weighed mean differences (WMD, 95\% CI) were similar in Asian versus non-Asian patients regarding the reductions in $\mathrm{HbAlc}-0.60$ $(-0.68,-0.53) \%$ versus $-0.54(-0.59,-0.49) \%(\mathrm{p}=0.568)$, FPG $-1.37(-1.53,-1.22)$ $\mathrm{mmol} / 1$ vs $-1.37(-1.47,-1.27) \mathrm{mmol} / \mathrm{l}(\mathrm{p}=0.627)$, BW when expressed in percentage of baseline BW $-2.23(-2.55,-1.90) \%$ vs $-2.16(-2.37,-1.96) \%(\mathrm{p}=0.324)$, and SBP -4.53 $(-5.53,-3.53) \mathrm{mmHg}$ vs $-4.06(-4.83,-3.29) \mathrm{mmHg})(\mathrm{p}=0.223)$. In conclusion, clinical efficacy of SGLT2i, as an add-on treatment to metformin monotherapy in patients with T2DM, is similar in Asian versus non-Asian patients, despite known ethnic differences in phenotype and pathophysiology of T2DM.
\end{abstract}

Keywords: blood pressure, body weight, combined therapy, glucose control, HbAlc, oral antidiabetic drug

\section{Introduction}

Metformin is still considered as the first-line pharmacological treatment for the management of type 2 diabetes (T2DM) combined with life-style measures (diet and exercise). ${ }^{1}$ In T2DM patients with atherosclerotic cardiovascular (CV) disease, heart failure and/or renal disease, sodium-glucose cotransporter type 2 inhibitors (SGLT2is) should be added to metformin whatever the level of glycated hemoglobin (HbA1c), as
Correspondence: André J Scheen Email andre.scheen@chuliege.be 
they have demonstrated both a CV and renal protection in high-risk patients, independently of glucose control. ${ }^{1}$ In patients with T2DM but without such comorbidities, the objective is to reach individualized HbAlc target if not attained with metformin monotherapy. SGLT2is may be added to metformin, ${ }^{2,3}$ but are in competition with other glucose-lowering agents, especially dipeptidyl peptidase-4 inhibitors (DPP-4is). ${ }^{4,5}$ When compared to DPP-4is, SGLT2is have the advantage to promote weight loss and reduce arterial blood pressure, two effects that may contribute to the $\mathrm{CV}$ protection. ${ }^{6}$

Most studies have been performed in non-Asian (mainly Caucasian) patients. However, some SGLT2is are commercialized in Asia (Japan, Korea, China, India), but not in North America or in Europe. Furthermore, Asian patients have a different phenotype of T2DM with a lower prevalence of obesity (yet an increased propensity for visceral adiposity) and a more marked defect in insulin secretion. $^{7}$ These differences may impact the treatment response to glucose-lowering agents. ${ }^{8,9}$ For instance, glucagon-like peptide-1 receptor agonists (GLP-1 RAs) ${ }^{10,11}$ and DPP-4is ${ }^{12,13}$ exert a greater reduction in HbAlc in Asian than in non-Asian patients with T2DM. A recent meta-regression of randomized controlled trials (RCTs) indicated the hypoglycemic efficacy of SGLT2is/DPP-4is combination is higher in Asians than in other ethnic populations, and the differences in body mass index across ethnic groups may mediate this effect. ${ }^{14}$

The primary renal mechanism of action of SGLT2is is an insulin-independent process. ${ }^{15,16}$ Nevertheless, both insulin secretion and insulin action could be indirectly improved when using an SGLT2i in patients with T2DM because of the reduction in glucose toxicity that is known to alter both beta-cell function and tissue insulin sensitivity. ${ }^{17,18}$ Thus, even if it is unknown whether there may exist inter-ethnic differences in the expression of sodium-glucose cotransporters in the renal tubules, different responses to SGLT2is might be observed between Asian and non-Asian patients with T2DM due to variable indirect effects on either insulin secretion or insulin action. A meta-analysis that compared the efficacy of SGLT2is showed no significant difference in HbA1c, body weight and systolic blood pressure (SBP) reductions between Asian and non-Asian patients with T2DM. ${ }^{19}$ However, this meta-analysis combined different types of background therapies, from diet and exercise alone to insulin therapy. Background therapy of patients with T2DM may influence the amplitude of the reduction in HbAlc when another glucose-lowering medication, including an SGLT2i, is added., ${ }^{3,20}$
The present work will restrict the analysis to a more homogeneous population, ie patients treated with metformin as monotherapy. This population is of special interest as the choice of the best glucose-lowering medication to be added to the first-line drug metformin ${ }^{1}$ remains a challenge for most clinicians, especially in primary care. ${ }^{21-23}$

The aim of this systematic review of RCTs is to compare the efficacy of SGLT2is versus placebo on glucose control, as assessed by changes in $\mathrm{HbA} 1 \mathrm{c}$ and fasting plasma glucose (FPG), weight loss and arterial blood pressure in non-Asian versus Asian patients with T2DM treated with life-style and metformin. The effects of SGLTis on cardiovascular outcomes will not be considered in the present review. ${ }^{24}$ Of note, in EMPA-REG OUTCOME, reductions in the risk of CV outcomes and mortality with empagliflozin in Asian patients with T2DM and established CV disease were consistent with those observed in the overall trial population. ${ }^{25}$

\section{Materials and Methods \\ Data Sources and Search Strategy}

Electronic searches were performed in Pubmed, Embase and ClinicalTrials.gov site from January 1, 2010 to March 31, 2020 using the following search terms: "sodium-glucose cotransporter type 2 inhibitor" OR "SGLT2 inhibitor" OR "SGLT-2 inhibitor". A first filter was used to select RCTs. Each term corresponding to SGT2i was associated ("AND") with the term "metformin" OR with the term "placebo", separately and then in combination (Figure 1).

In a complementary approach, the same search was performed for each SGLT2i commercialized worldwide (canagliflozin, dapagliflozin, empagliflozin, ertugliflozin), in Japan (ipragliflozin, luseogliflozin, tofogliflozin), and in India (remoglifozin). The reference lists of several systematic reviews and meta-analyses dedicated to SGLT2is , 26,27 $^{2,2}$ and of eligible related articles were manually examined to identify any additional publication relevant to the present study. Search for duplicates was done manually and using Endnote. Two independent researchers (A.S. and M.M., see acknowledgment) screened the literature, analyzed the selected studies and summarized the search results, using the same inclusion and exclusion criteria. Any resulting discrepancies were resolved by mutual discussion.

\section{Inclusion and Exclusion Criteria}

Inclusion criteria were as follows: (a) RCTs with a duration of at least 12 weeks and a maximum of 52 weeks, which randomized at least $40 \mathrm{~T} 2 \mathrm{DM}$ individuals in the arm of 


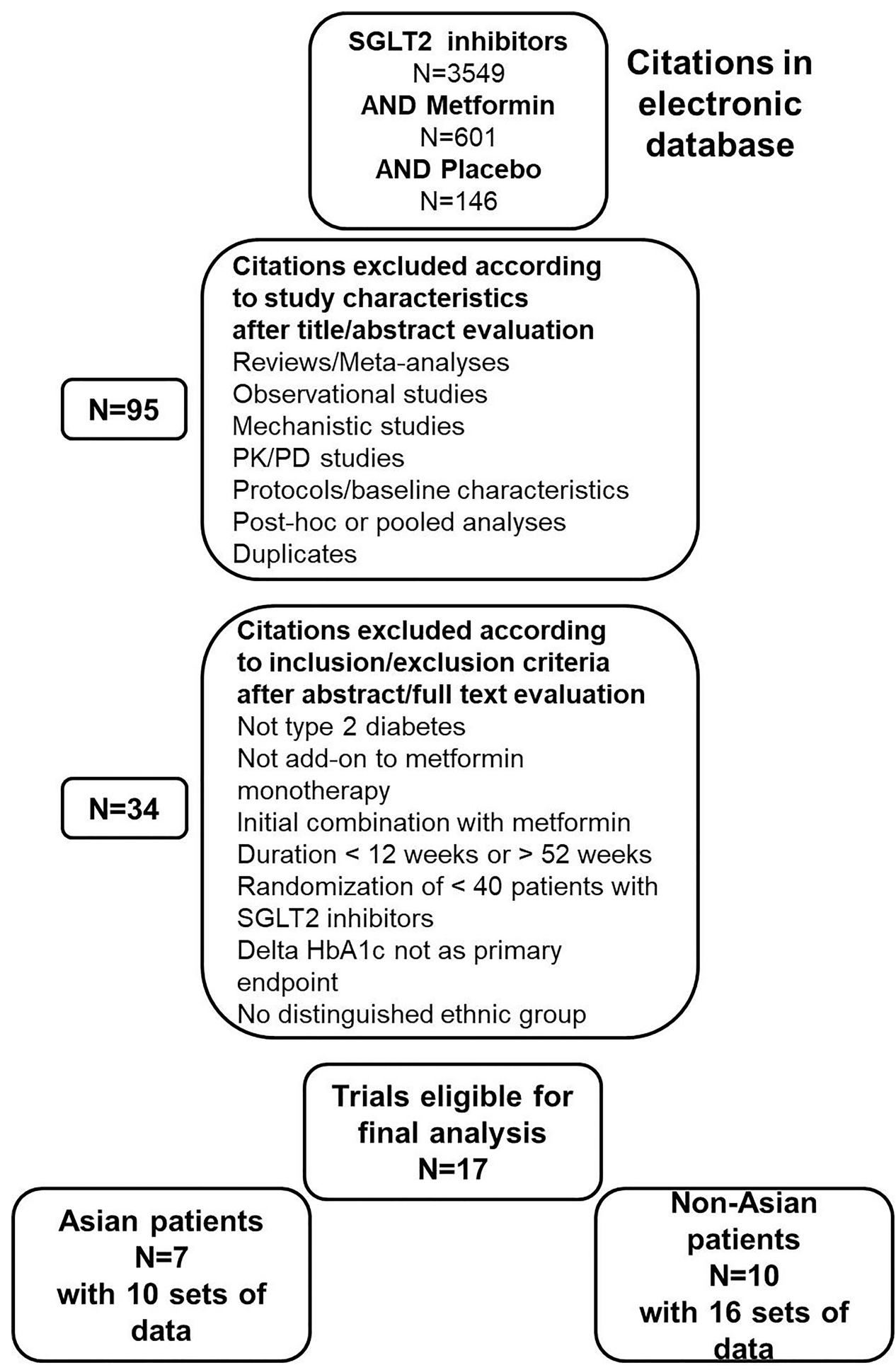

Figure I Flow chart of study selection process.

Abbreviations: HbAlc, glycated hemoglobin; PD, pharmacodynamics; PK, pharmacokinetics; SGLT2i, sodium-glucose cotransporter 2 inhibitor.

interest (SGLT2i) and used a placebo as comparator; (b) participants with T2DM and without renal insufficiency (estimated glomerular filtration rate $>60 \mathrm{~mL} / \mathrm{min} / 1.73 \mathrm{~m} 2$ ), who were treated with lifestyle plus metformin monotherapy and had baseline $\mathrm{HbAlc}>7 \%(53 \mathrm{mmol} / \mathrm{mol})$ at randomization; (c) detailed information available about the ethnic origin of the population; (d) in RCTs that tested different doses of SGLT2i (dose-finding studies), only the arms that evaluated commercialized doses of the SGLT2 $\mathrm{i}$ were selected for the analyses; and (e) placebo-corrected 
reduction in $\mathrm{HbAlc}$ from baseline $\mathrm{HbAlc}$ (delta $\mathrm{HbAlc}$ ) considered as the primary (or key-secondary) endpoint.

Exclusion criteria were as follows: (a) observational studies and non-randomized trials; (b) RCTs involving healthy subjects, non-diabetic patients with insulin resistance, patients with type 1 diabetes; (c) trials that randomized $<40$ patients with T2DM in the arm treated by an SGLT2i; (d) RCTs with a duration of less than 12 weeks or more than 52 weeks; (e) trials that evaluated initial combination of metformin plus an SGLT2i in drug-naïve T2DM patients; (f) trials that evaluated T2DM patients receiving other glucose-lowering agents than metformin monotherapy or that used an active glucose-lowering agent rather than a placebo as a comparator.

\section{Data Extraction}

The following data were extracted from all studies: (a) trial characteristics (RCT, first author, publication year, type and daily dose of SGLT2i added to metformin, duration of therapy, timing of primary evaluation); (b) participant characteristics (type of diabetes, antidiabetes treatment at randomization, sample size, baseline $\mathrm{HbAlc}$; (c) ethnic groups separated as Asian versus nonAsian patients (RCTs that recruited $\geq 65 \%$ of non-Asian patients and $<20 \%$ of Asian patients were classified in the category of non-Asian RCTs); d) primary endpoint (delta HbA1c: change in HbAlc from baseline to time of interest: for studies of 52-week duration, but in which the primary endpoint was considered at 24-28 weeks, the latter results were taken into account; for studies with extension beyond 52 weeks, primary results at 52 weeks were considered for the analysis); e) baseline levels and changes versus baseline of fasting plasma glucose (FPG), body weight $(\mathrm{BW})$ and systolic blood pressure (SBP) considered as key-secondary endpoints.

\section{Data Synthesis and Statistical Analysis}

Mean $( \pm \mathrm{SD})$ values were calculated from mean $\mathrm{HbAlc}$ levels at baseline and mean delta HbAlc (changes in $\mathrm{HbAlc}$ from baseline to time of primary endpoint) reported in the different RCTs. When SD was not available in the original publication, it was calculated using values of standard error of the mean (SE) or $95 \%$ confidence interval $(95 \%$ CI). Placebo-corrected mean weighted difference (WMD), adjusted for the number of patients in each RCT, was compared in non-Asian and Asian patients with T2DM. Statistical differences versus baseline levels and between the two ethnic groups were calculated using paired and unpaired $t$-tests, respectively. Calculations and forest plots have been done using the review manager 5.3 program.

\section{Results}

\section{Study Characteristics}

The study selection process is depicted in Figure 1. A total of 3549 references were identified through the initial electronic search. When combined with the term "metformin", the number of references was reduced to 601 . Subsequent combination with "placebo" allowed to reduce the number of references to 146. From this first set of references, we excluded citations based upon study characteristics after title/abstract evaluation ( $\mathrm{n}=95)$ and subsequently other citations based upon inclusion/exclusion criteria after abstract/ full-text evaluation $(n=34)$. At the end of this search strategy, 17 RCTs that fulfilled all criteria were identified and were separated according to the ethnic group in two categories: RCTs that recruited Asian patients versus RCTs that recruited exclusively or mostly ( $>65 \%)$ non-Asian patients. In the end, we identified 7 eligible RCTs ( 3 of them tested two doses, thus a total of 10 sets of data: $n=1164$ ) in Asian patients ${ }^{28-34}$ and 10 eligible RCTs (6 of them tested two different doses, thus a total of 16 sets of data: $n=2482$ ) in non-Asian patients. ${ }^{35-45}$ The results of one RCT were reported in two different complementary publications. ${ }^{38,39}$ In addition, two international studies recruited a mix population with both non-Asian and Asian patients with T2DM, one that tested ertugliflozin (respective proportions of ethnic groups not mentioned ${ }^{46}$ and one that evaluated empagliflozin (53\% non-Asian and 46\% Asian patients). ${ }^{47}$ As no separate results were provided according to ethnicity, these two studies have not been included in the main analyses comparing Asian versus non-Asian patients and their results will be shown separately.

\section{HbAlc Reduction in Non-Asian vs Asian Patients}

The effects of SGLT2is versus placebo on HbA1c in people with T2DM treated with metformin monotherapy are shown in Table 1 for Asian patients and in Table 2 for non-Asian patients. SGLT2i treatment was associated with a significant $\mathrm{HbAlc}$ reduction in both ethnic groups. No significant differences were observed neither in baseline $\mathrm{HbAlc}$ levels $(7.98 \pm 0.19$ versus $7.89 \pm 0.27, p=0.190)$ nor in the HbA1c reduction from baseline between Asian and non-Asian patients: WMD $-0.60(-0.68,-0.53) \%$ versus -0.54 $(-0.59,-0.49) \%$, respectively, $\mathrm{p}=0.568$. As empagliflozin 
Table I Effects of SGLT2is on HbAlc in Placebo-Controlled Randomized Clinical Trials That Recruited Asian Patients with T2DM Insufficiently Controlled on Metformin Monotherapy

\begin{tabular}{|c|c|c|c|c|c|c|c|c|c|c|}
\hline \multicolumn{4}{|c|}{ Characteristics } & \multicolumn{3}{|c|}{ SGLT2 Inhibitor } & \multicolumn{3}{|c|}{ Placebo } & \multirow{2}{*}{$\begin{array}{l}\text { Placebo- } \\
\text { Corrected Delta } \\
\text { HbAlc } \\
\text { Mean }(95 \% \mathrm{Cl})\end{array}$} \\
\hline References & Countries & $\begin{array}{l}\text { SGLT2i } \\
\text { Daily Dose } \\
\text { (mg) }\end{array}$ & $\begin{array}{l}\text { Duration } \\
\text { (Weeks) }\end{array}$ & $\mathbf{N}$ & $\begin{array}{l}\text { Baseline } \\
\text { HbAlc } \\
\text { (Mean } \pm \\
\text { SD) }\end{array}$ & $\begin{array}{l}\text { HbAlc } \\
\text { Delta vs } \\
\text { Baseline } \\
\text { (Mean } \pm \text { SD) }\end{array}$ & $\mathbf{N}$ & $\begin{array}{l}\text { Baseline } \\
\text { HbAlc } \\
\text { (Mean } \pm \\
\text { SD) }\end{array}$ & $\begin{array}{l}\text { HbAlc } \\
\text { Delta vs } \\
\text { Baseline } \\
\text { (Mean } \pm \text { SD) }\end{array}$ & \\
\hline \multirow[t]{2}{*}{$\begin{array}{l}\text { ji et al } \\
2015^{28}\end{array}$} & \multirow[t]{2}{*}{ China } & $\begin{array}{l}\text { Canagliflozin } \\
100\end{array}$ & 18 & 108 & $8.0 \pm 0.9$ & $-1.03 \pm 1.76$ & 110 & $7.9 \pm 0.9$ & $-0.51 \pm 1.68$ & $\begin{array}{l}-0.52(-0.72 \\
-0.32) p<0.001\end{array}$ \\
\hline & & $\begin{array}{l}\text { Canagliflozin } \\
300\end{array}$ & 18 & 112 & $7.8 \pm 0.8$ & $-1.12 \pm 1.69$ & 110 & $7.9 \pm 0.9$ & $-0.51 \pm 1.68$ & $\begin{array}{l}-0.60(-0.80 \\
-0.40) p<0.001\end{array}$ \\
\hline \multirow[t]{2}{*}{$\begin{array}{l}\text { Yang et al } \\
2016^{29}\end{array}$} & \multirow[t]{2}{*}{$\begin{array}{l}\text { China, India, } \\
\text { South Korea }\end{array}$} & $\begin{array}{l}\text { Dapagliflozin } \\
5\end{array}$ & 24 & 147 & $8.09 \pm 0.72$ & $-0.82 \pm 0.74$ & 145 & $8.13 \pm 0.85$ & $-0.59 \pm 1.06$ & $\begin{array}{l}-0.59(-0.76 \\
-0.42) p<0.001\end{array}$ \\
\hline & & $\begin{array}{l}\text { Dapagliflozin } \\
10\end{array}$ & 24 & 152 & $8.17 \pm 0.84$ & $-0.85 \pm 0.72$ & 145 & $8.13 \pm 0.85$ & $-0.62 \pm 1.04$ & $\begin{array}{l}-0.62(-0.79,-0.45) \\
p<0.001\end{array}$ \\
\hline \multirow[t]{2}{*}{$\begin{array}{l}\text { ji et al } \\
2019^{30}\end{array}$} & \multirow[t]{2}{*}{ China } & $\begin{array}{l}\text { Ertugliflozin } \\
5\end{array}$ & 26 & 170 & $8.10 \pm 0.90$ & $-1.00 \pm 0.90$ & 167 & $8.10 \pm 1.00$ & $-0.20 \pm 0.80$ & $\begin{array}{l}-0.8(-1.0,-0.6) \\
p<0.001\end{array}$ \\
\hline & & $\begin{array}{l}\text { Ertugliflozin } \\
15\end{array}$ & 26 & 169 & $8.10 \pm 0.90$ & $-0.90 \pm 0.80$ & 167 & $8.10 \pm 1.00$ & $-0.20 \pm 0.80$ & $\begin{array}{l}-0.7(-0.9,-0.5) \\
p<0.001\end{array}$ \\
\hline $\begin{array}{l}\text { Kashiwagi } \\
\text { et al } 2015^{31}\end{array}$ & Japan & $\begin{array}{l}\text { Ipragliflozin } \\
50\end{array}$ & 24 & 112 & $8.25 \pm 0.72$ & $-0.87 \pm 0.65$ & 56 & $8.38 \pm 0.74$ & $+0.38 \pm 0.70$ & $\begin{array}{l}-1.30(-1.50 \\
-1.09) p<0.001\end{array}$ \\
\hline $\begin{array}{l}\text { Lu et al } \\
2016^{32}\end{array}$ & $\begin{array}{l}\text { South Korea, } \\
\text { Taiwan }\end{array}$ & $\begin{array}{l}\text { Ipragliflozin } \\
50\end{array}$ & 24 & 87 & $7.74 \pm 0.78$ & $-0.94 \pm 0.75$ & 83 & $7.75 \pm 0.71$ & $-0.47 \pm 0.81$ & $\begin{array}{l}-0.46(-0.66,- \\
0.27) p<0.001\end{array}$ \\
\hline $\begin{array}{l}\text { Min et al } \\
2017^{33}\end{array}$ & South Korea & $\begin{array}{l}\text { Ipragliflozin } \\
50\end{array}$ & 24 & 43 & $7.67 \pm 0.85$ & $-0.97 \pm 0.81$ & 39 & $7.62 \pm 0.78$ & $-0.31 \pm 0.79$ & $\begin{array}{l}-0.60(-0.87 \\
-0.34) p<0.001\end{array}$ \\
\hline $\begin{array}{l}\text { Ikeda et al } \\
2015^{34}(*)\end{array}$ & Japan & $\begin{array}{l}\text { Tofogliflozin } \\
20\end{array}$ & 12 & 64 & $7.92 \pm 0.79$ & $-0.768 \pm 0.59$ & 66 & $7.88 \pm 0.69$ & $-0.269 \pm 0.59$ & -0.5 (NA) $p<0.001$ \\
\hline
\end{tabular}

Notes: $\left(^{*}\right) 62 \%$ patients on metformin monotherapy, $38 \%$ on diet alone. Results correspond to the whole group in absence of separate analysis.

Abbreviations: $\mathrm{Cl}$, confidence interval; HbAlc, glycated hemoglobin (mmol/mol); N, number of patients; NA, not available; SD, standard deviation; SGLT2i, sodium-glucose cotransporter type 2 inhibitor.

was not evaluated as add-on to metformin in Asian patients whereas tofogliflozin was not evaluated in non-Asian patients, we excluded these two studies and restricted the analysis to SGLT2is that were investigated in both ethnic populations (canagliflozin, dapagliflozin, ertugliflozin and ipragliflozin) and the overall results were not different (data not shown). Finally, no differences in the reduction in $\mathrm{HbAlc}$ were observed between Asian and non-Asian patients when studies were divided according to baseline $\mathrm{HbAlc}<8 \%$ $(-0.54 \pm 0.07$ versus $-0.53 \pm 0.16$, respectively, $\mathrm{p}=0.858)$ versus $\geq 8 \%(-0.76 \pm 0.28$ versus $-0.59 \pm 0.26$, respectively, $\mathrm{p}=0.345)$. These data are summarized in a forest plot metaanalysis, which showed some heterogeneity between studies in both ethnic groups, Asian (Figure 2) and non-Asian (Figure 3). These results are in agreement with the reductions in $\mathrm{HbAlc}$ reported in the two studies that recruited a mix of Asian and non-Asian patients with T2DM treated with metformin alone: placebo-corrected least square mean $-0.69 \%$ and $-0.72 \%$ with the add-on of ertugliflozin $5 \mathrm{mg}$ and $25 \mathrm{mg}$, respectively; ${ }^{46}-0.57 \%$ and $-0.64 \%$ with the addon of empagliflozin $10 \mathrm{mg}$ and $25 \mathrm{mg}$, respectively. ${ }^{47}$

\section{Other Efficacy Parameters}

The effects of SGLT2is versus placebo on FPG, BW and SBP, expressed as placebo-adjusted WMD, in Asian and non-Asian patients are shown in Tables 3 and 4, respectively. SGLT2i treatment was associated with a consistent and significant reduction in all three parameters in both ethnic groups. Reductions in diastolic blood pressure were generally about half of those noticed for SBP (data not shown). No significant differences were observed neither in baseline levels nor in SGLT2i-associated reductions (WMD) regarding FPG $(-1.37$ $(-1.53,-1.22) \mathrm{mmol} / \mathrm{l}$ versus $-1.37(-1.47,-1.27) \mathrm{mmol} / \mathrm{l}$, $\mathrm{p}=0.627)$ (Table 5) and SBP $(-4.53(-5.53,-3.53) \mathrm{mmHg}$ 


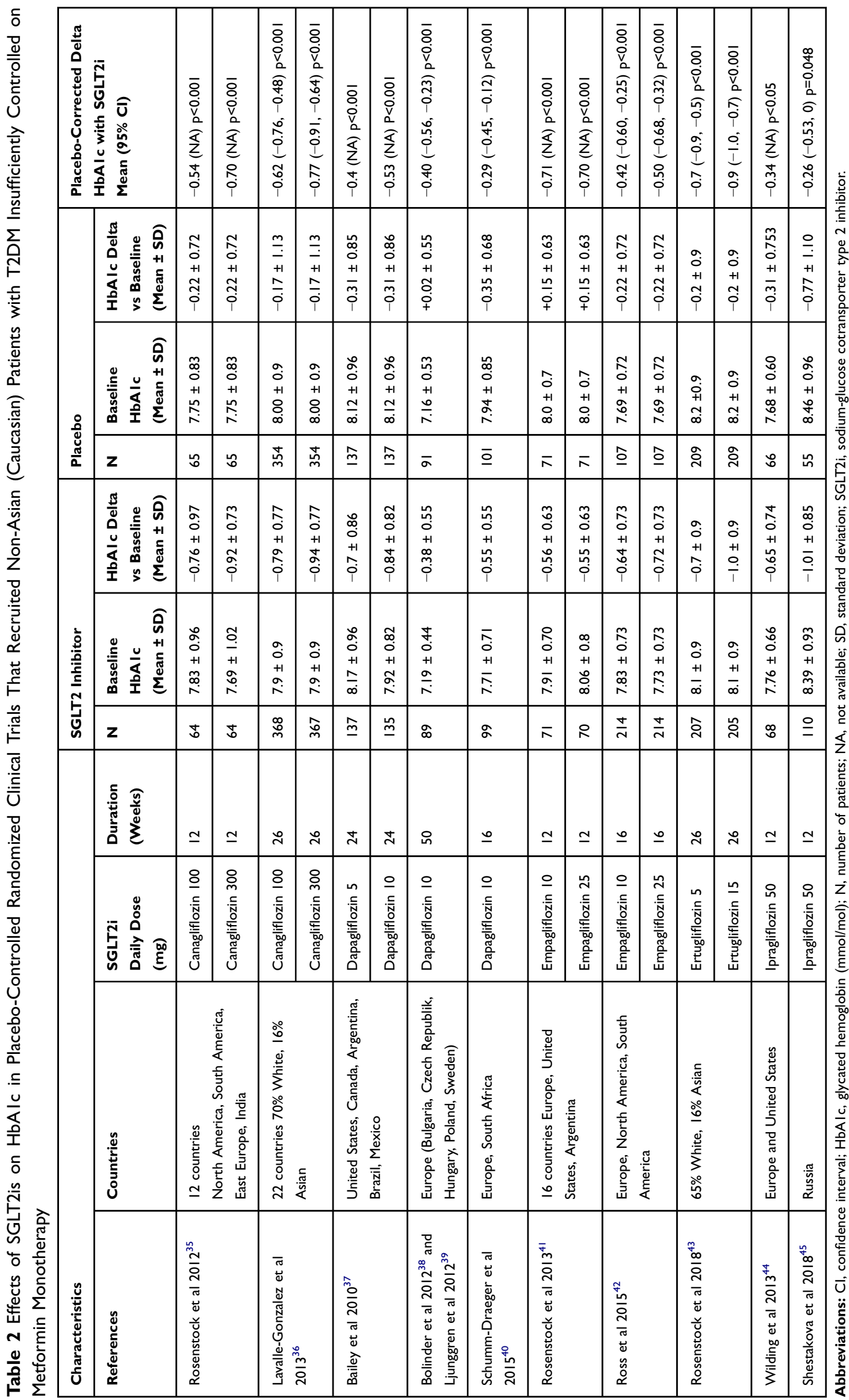




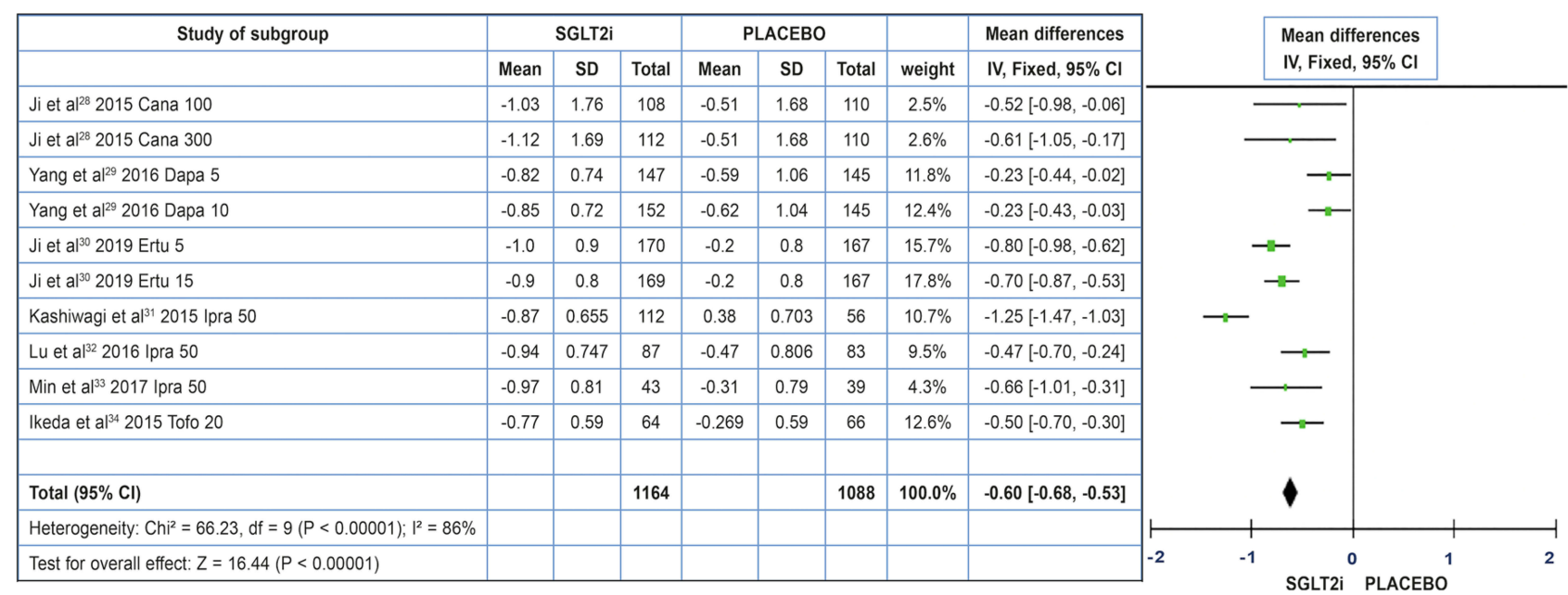

Figure 2 Meta-analysis of placebo-controlled randomized clinical trials that investigated the effects of SGLT2is on HbAlc in Asian patients with T2DM insufficiently controlled on metformin monotherapy.

Abbreviations: $\mathrm{Cl}$, confidence interval; HbAlc, glycated hemoglobin (mmol/mol); IV, inverse variance; SD, standard deviation; SGLT2i, sodium-glucose cotransporter type 2 inhibitor.

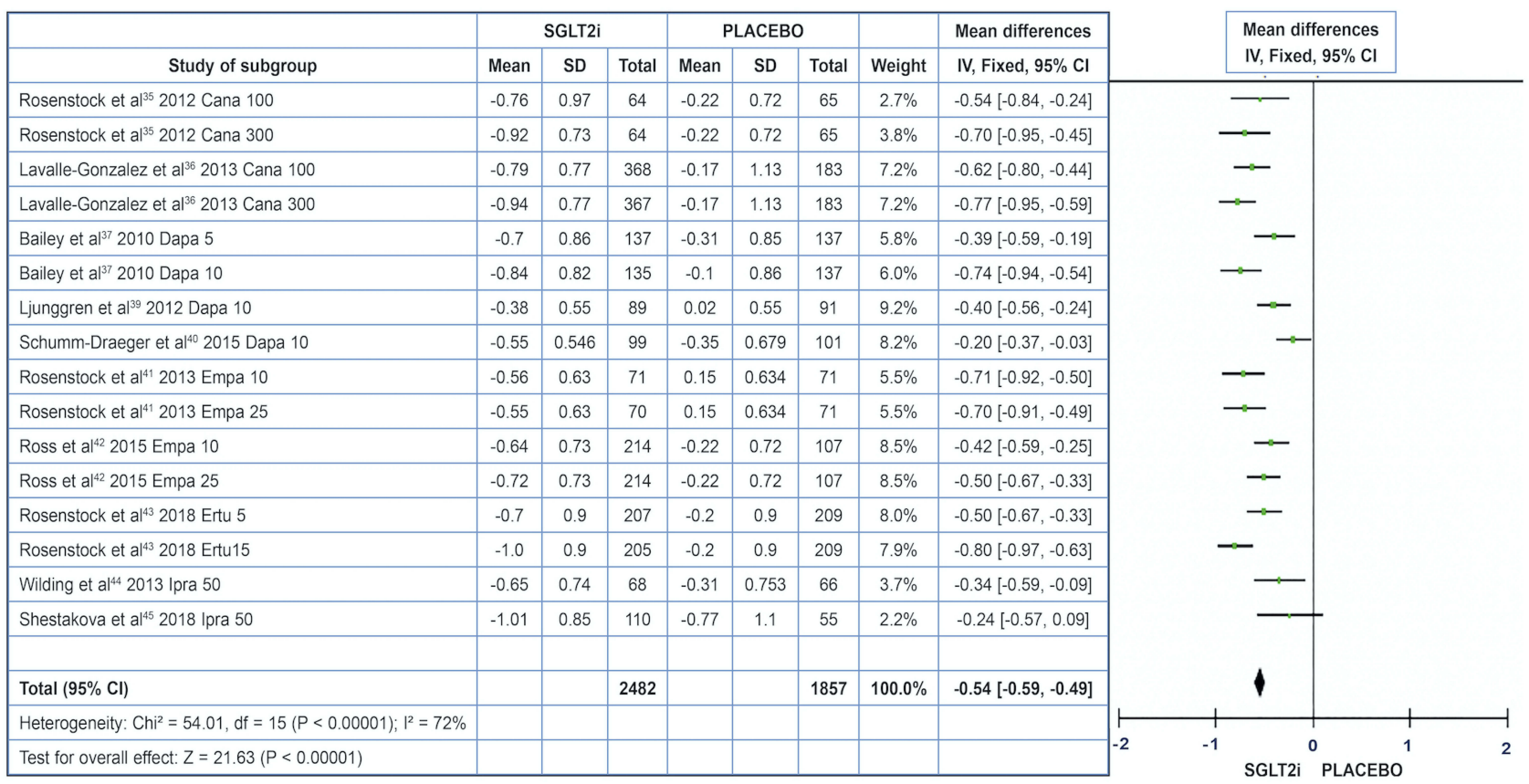

Figure 3 Meta-analysis of placebo-controlled randomized clinical trials that investigated the effects of SGLT2is on HbAlc in non-Asian (Caucasian) patients with T2DM insufficiently controlled on metformin monotherapy.

Abbreviations: $\mathrm{Cl}$, confidence interval; $\mathrm{HbAlc}$, glycated hemoglobin; IV, inverse variance; SD, standard deviation; SGLT2i, sodium-glucose cotransporter type 2 inhibitor.

versus $-4.06(-4.83,-3.29) \mathrm{mmHg}, \mathrm{p}=0.223)$ (Table 6) between Asian and non-Asian patients, respectively. Baseline BW was significantly lower in Asian compared to non-Asian patients $(71.5$ versus $88.0, \mathrm{p}<0.001)$. The $\mathrm{BW}$ reduction observed with SGLT2i tended to be slightly lower in Asian than in non-Asian patients when expressed in $\mathrm{kg}$ $(-1.60(-1.84,-1.37) \mathrm{kg}$ versus $-1.91(-2.09,-1.73) \mathrm{kg}$, $\mathrm{p}=0.090)$, but this trend disappeared when changes were expressed in percentage of initial BW: $-2.23(-2.55,-1.90)$ $\%$ versus $-2.16(-2.37,-1.96) \%, p=0.324)$ (Table 6$)$. These effects of SGLT2is on FPG, BW and SBP are illustrated in three forest plot meta-analyses (see Figures S1-S3 in supplementary materials). Of note, no heterogeneity was detected between studies for BW and SBP, in contrast to results evaluating glucose control (HbAlc in Figures 2 and 3 and FPG in Figure $\mathrm{S} 1)$. 


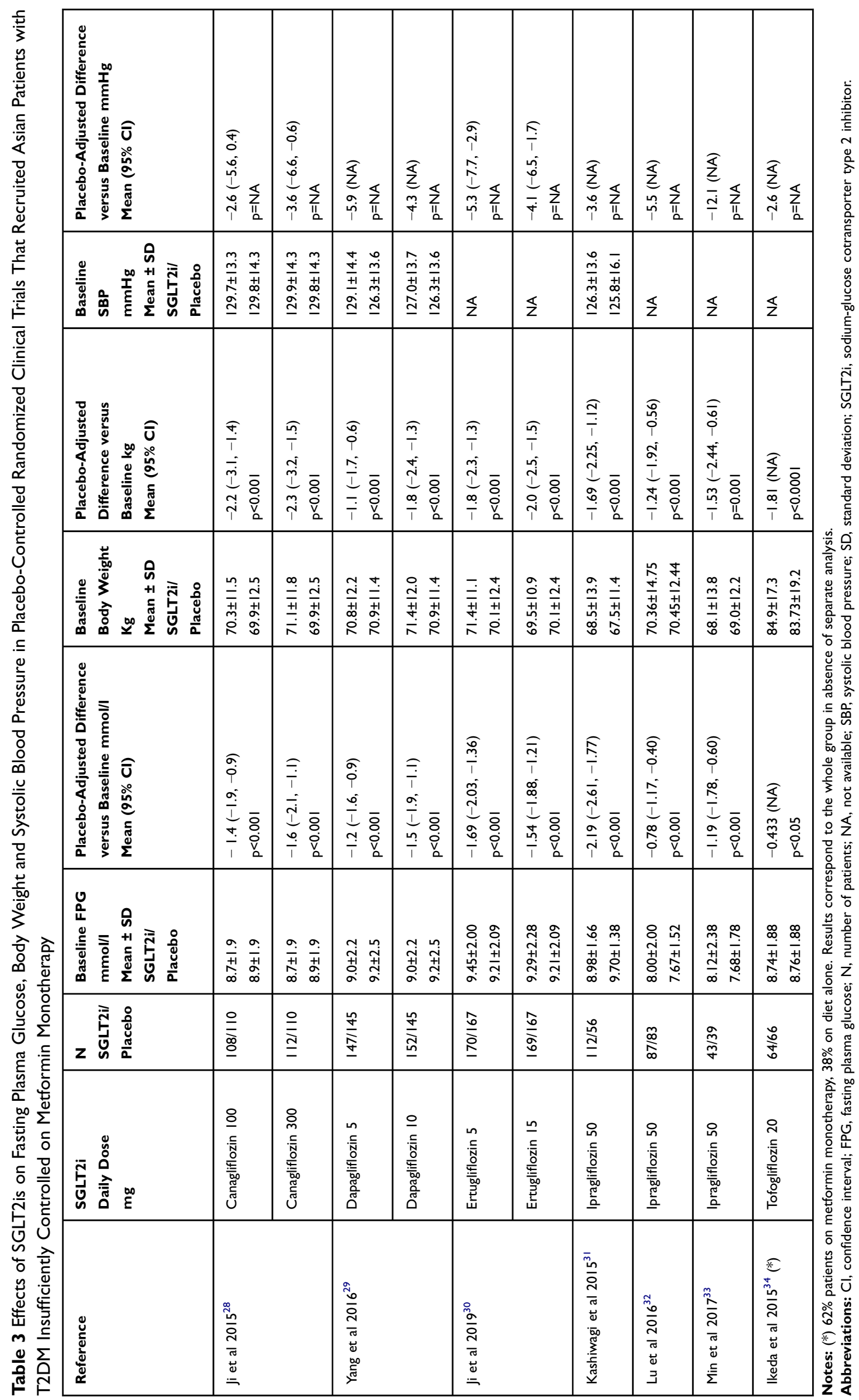




\begin{tabular}{|c|c|c|c|c|c|c|c|c|c|c|c|c|}
\hline 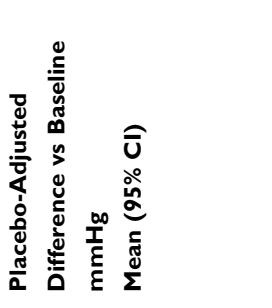 & 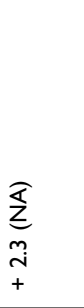 & 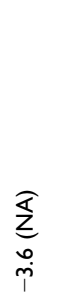 & 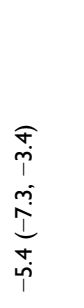 & 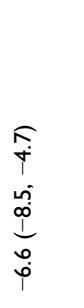 & $\frac{\stackrel{\nwarrow}{z}}{\dot{y}}$ & 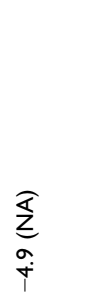 & 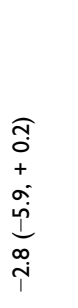 & $\begin{array}{l}\frac{a}{2} \\
\vdots \\
\frac{1}{1}\end{array}$ & $\begin{array}{l}\underset{T}{z} \\
\frac{2}{\mathrm{n}} \\
\mathrm{i}\end{array}$ & $\begin{array}{l}\frac{\pi}{z} \\
m \\
i \\
i\end{array}$ & 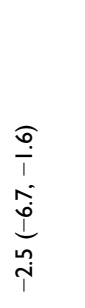 & 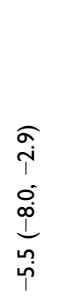 \\
\hline 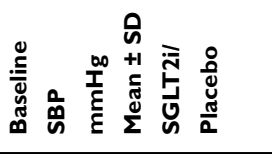 & 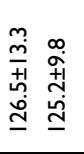 & 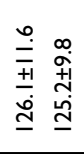 & 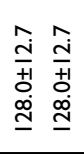 & 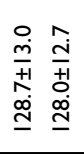 & 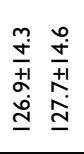 & 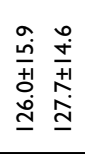 & 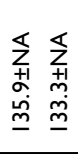 & 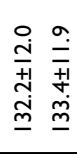 & 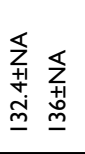 & 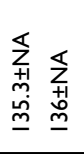 & 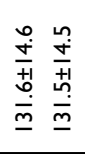 & 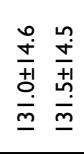 \\
\hline 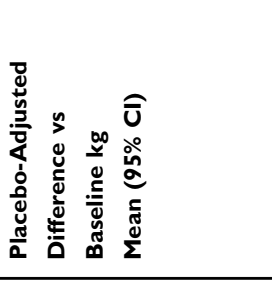 & 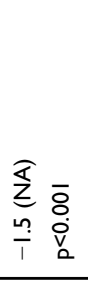 & 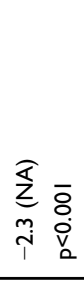 & 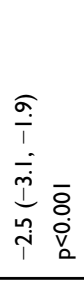 & 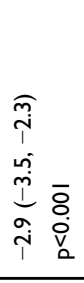 & $\begin{array}{l}\bar{z} \\
\underline{z} \\
\bar{i} \\
i \\
\dot{i} \\
\end{array}$ & 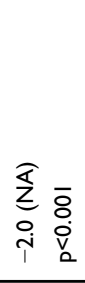 & 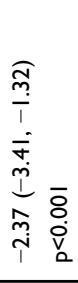 & 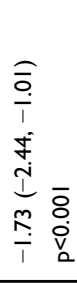 & 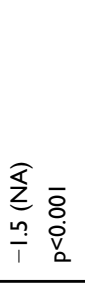 & 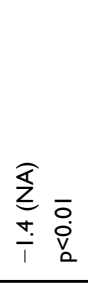 & 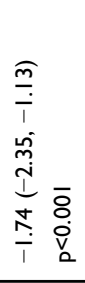 & 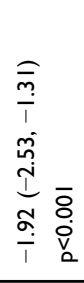 \\
\hline 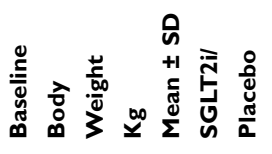 & 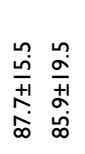 & 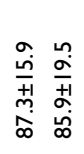 & 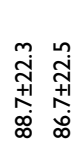 & 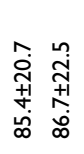 & 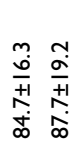 & 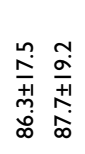 & 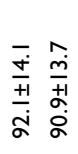 & 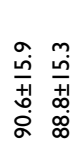 & 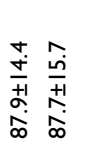 & 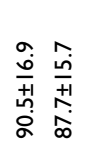 & 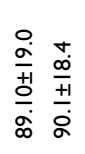 & 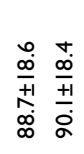 \\
\hline 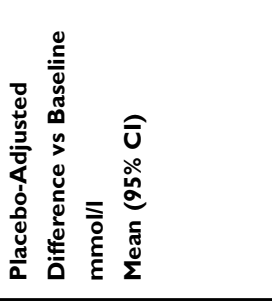 & 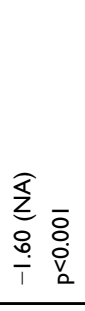 & 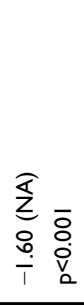 & 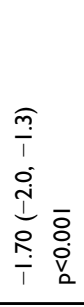 & 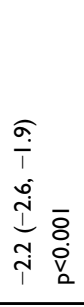 & 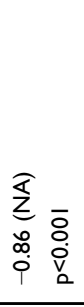 & 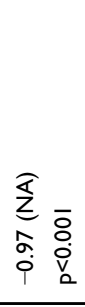 & 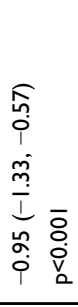 & 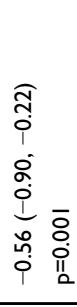 & 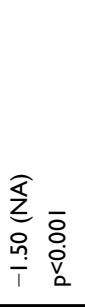 & 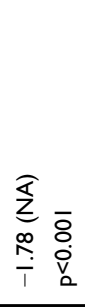 & 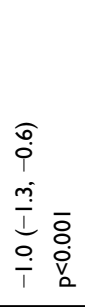 & 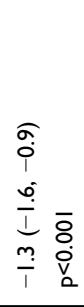 \\
\hline 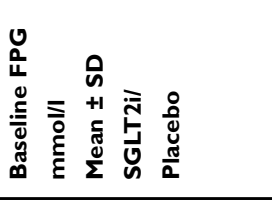 & 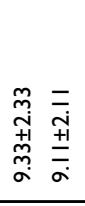 & 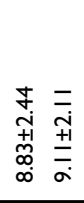 & 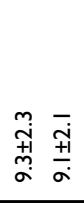 & 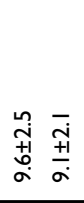 & 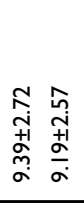 & 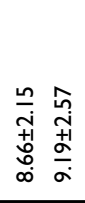 & 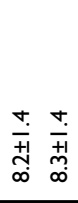 & 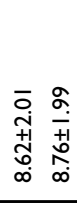 & 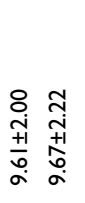 & 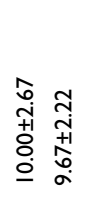 & 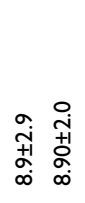 & 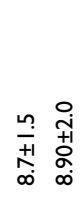 \\
\hline 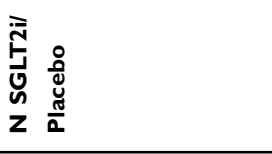 & 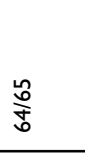 & \begin{tabular}{l} 
峖 \\
\multirow{5}{0}{}
\end{tabular} & 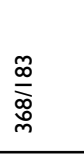 & $\underset{\substack{\infty\\
}}{\stackrel{\infty}{\infty}}$ & $\underset{\underline{m}}{\stackrel{\hat{m}}{\underline{m}}}$ & 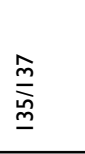 & $\begin{array}{l}\bar{\alpha} \\
\bar{\infty}\end{array}$ & $\frac{\overline{0}}{\alpha}$ & $\stackrel{\Sigma}{\aleph}$ & 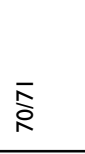 & $\frac{\hat{O}}{\frac{\partial}{N}}$ & $\frac{\hat{O}}{\frac{\partial}{N}}$ \\
\hline 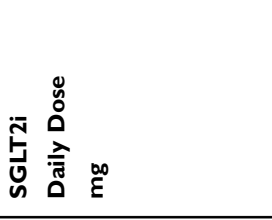 & 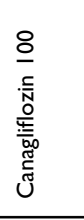 & 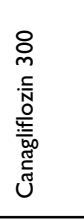 & 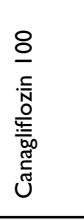 & 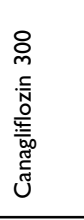 & 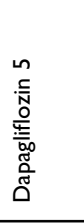 & 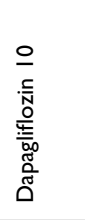 & 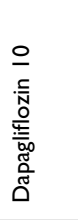 & 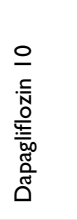 & 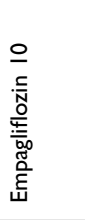 & 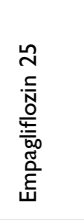 & 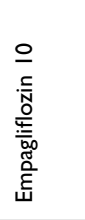 & 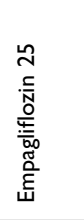 \\
\hline 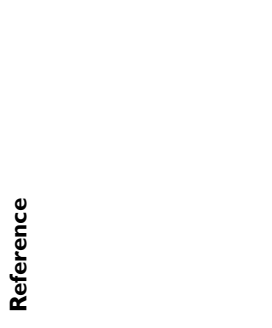 & 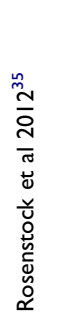 & & 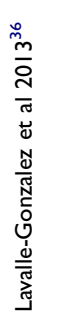 & & 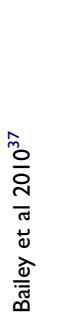 & & 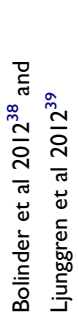 & 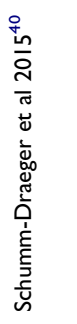 & 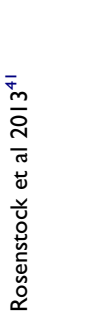 & & 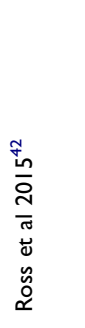 & \\
\hline
\end{tabular}




\begin{tabular}{|c|c|c|c|c|}
\hline 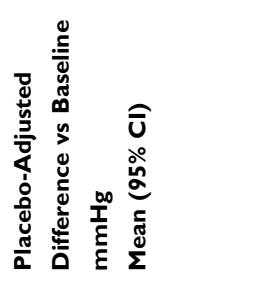 & $\begin{array}{l}\underset{\Sigma}{z} \\
\hat{i}\end{array}$ & 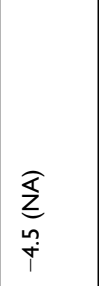 & 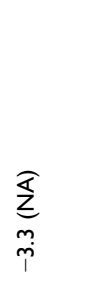 & $\begin{array}{l}\underset{\nwarrow}{z} \\
\stackrel{0}{+} \\
\dot{1}\end{array}$ \\
\hline 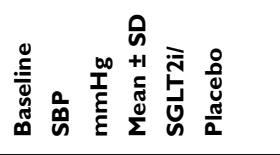 & 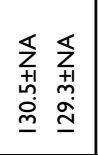 & 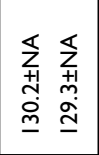 & $\Sigma \bar{z}$ & $\mathbb{z} \frac{\pi}{z}$ \\
\hline 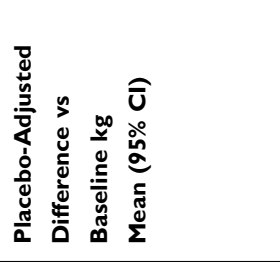 & 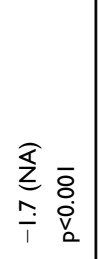 & 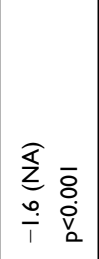 & 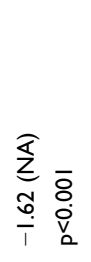 & 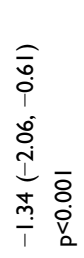 \\
\hline 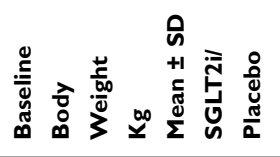 & 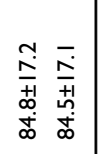 & 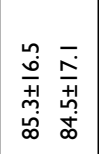 & 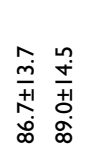 & 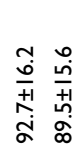 \\
\hline 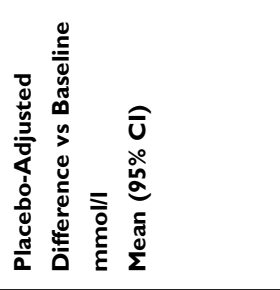 & 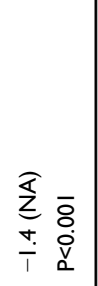 & $\begin{array}{ll}\bar{z} & \bar{o} \\
\bar{i} & \dot{b} \\
\dot{i} & \end{array}$ & 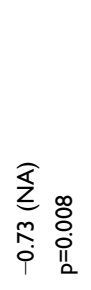 & 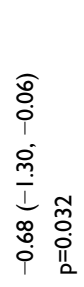 \\
\hline 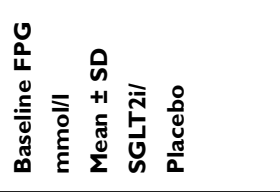 & 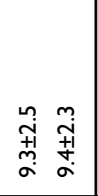 & 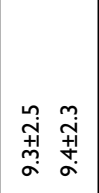 & 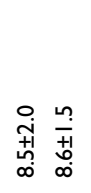 & 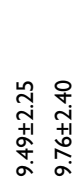 \\
\hline 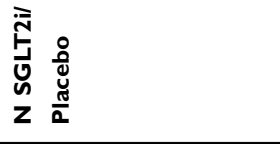 & 突 & 商 & 总 & $\stackrel{\text { 足 }}{\underline{\underline{O}}}$ \\
\hline 突 & 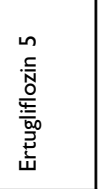 & 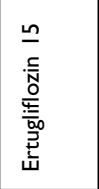 & 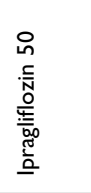 & 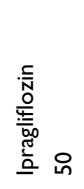 \\
\hline 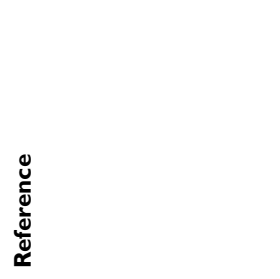 & 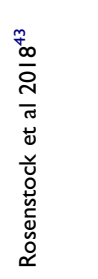 & & 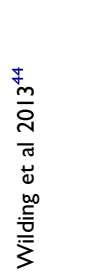 & 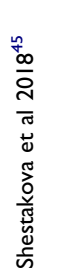 \\
\hline
\end{tabular}

\section{Discussion}

Our results show that the glucose-lowering efficacy of SGLT2is, when added to metformin monotherapy, is similar in non-Asian and Asian patients with T2DM, considering the reductions in $\mathrm{HbAlc}$ and in FPG. These data confirm a previous meta-analysis of all RCTs that investigated SGLT2is added to any type of glucose-lowering therapies ranging from diet alone to insulin regimen. ${ }^{19}$ We also recently reported similar antihyperglycemic effects of SGLT2is in non-Asian and Asian patients with T2DM and chronic kidney disease. ${ }^{48}$

These results contrast with those previously reported with incretin-based glucose-lowering therapies. Indeed, several meta-analyses showed a greater glucose-lowering effect of DPP-4is ${ }^{12,13}$ and of injectable GLP-1 RAs ${ }^{10}$ in Asian compared with non-Asian patients with $\mathrm{T} 2 \mathrm{DM}$, a finding recently confirmed with the combination of DPP-4i/SGLT $2 \mathrm{i}^{14}$ and with oral semaglutide. ${ }^{11}$ The difference between these pharmacological classes may be explained by the fact that SGLT2is exert their glucose-lowering effect independently of insulin, ${ }^{3,15,16}$ in contrast with the mode of action of DPP4 is (acting as incretin potentiators) and GLP-1 RAs (acting as incretin mimetics), which both enhance endogenous insulin secretion. ${ }^{49}$ It is known that Asian patients with T2DM have a more profound deficit in insulin secretion than non-Asian patients. $^{7}$ Asian patients with T2DM are also leaner than non-Asian (Caucasian) patients. As a clear correlation between body mass index and HbAlc-lowering effect of DPP-4is was shown in Asian-dominant studies, but not in non-Asian-dominant studies, it has been suggested that DPP4is may have better glucose-lowering efficacy in Asian patients with T2DM because they have lower BW compared to Caucasian patients. ${ }^{7}, 12$ Obviously, such an inter-ethnic difference in the glucose-lowering efficacy is not observed with SGLT2is.

Our results confirm that SGLT2is when added to metformin monotherapy are associated with a significant BW reduction. Because of significantly lower BW in Asian compared to non-Asian patients at baseline, a slight numerical difference in the placebo-adjusted BW reductions was noticed when expressed in $\mathrm{kg}$. However, the difference completely disappeared when results were expressed in percentage of baseline BW. The amount of weight loss in our analysis are in agreement with that previously reported with different SGLT2is and different dosages,${ }^{50}$ including in studies in East-Asian patients. ${ }^{51}$ Previous studies have shown that the overall weight reduction seen with SGLT2is is 
Table 5 Differences Between Asian versus Non-Asian Patients with Type 2 Diabetes Regarding the Effects of SGLT2i on Glucose Control

\begin{tabular}{|c|c|c|c|}
\hline Parameters & $\begin{array}{l}\text { Asian Patients } \\
\text { SGLT2i versus Placebo } \\
(n=1 \mid 64 \text { versus } n=1088)\end{array}$ & $\begin{array}{l}\text { Non-Asian Patients } \\
\text { SGLT2i versus } \text { Placebo } \\
(n=2482 \text { versus } n=1857)\end{array}$ & $P$ values \\
\hline \multicolumn{4}{|l|}{ Glycated hemoglobin (HbAlc, \%) } \\
\hline $\begin{array}{l}\text { Baseline values (SGLT2i/placebo) } \\
\text { Delta versus baseline (absolute \%) } \\
\text { Delta versus baseline (relative \%) }\end{array}$ & $\begin{array}{l}7.98 \pm 0.19 / 7.99 \pm 0.22 \\
-0.60(-0.68,-0.53) \\
-5.74(-6.62,-4.87)\end{array}$ & $\begin{array}{l}7.89 \pm 0.27 / 7.92 \pm 0.30 \\
-0.54(-0.59,-0.49) \\
-6.90(-7.52,-6.28)\end{array}$ & $\begin{array}{l}0.189 / 0.540 \\
0.586 \\
0.880\end{array}$ \\
\hline \multicolumn{4}{|l|}{ Fasting plasma glucose $(\mathrm{mmol} / \mathrm{l})$} \\
\hline $\begin{array}{l}\text { Baseline values (SGLT2i/placebo) } \\
\text { Delta versus baseline }(\mathrm{mmol} / \mathrm{l}) \\
\text { Delta versus baseline }(\%)\end{array}$ & $\begin{array}{l}8.80 \pm 0.46 / 8.84 \pm 0.67 \\
-1.37(-1.53,-1.22) \\
-15.34(-17.05,-13.63)\end{array}$ & $\begin{array}{l}9.11 \pm 0.49 / 9.14 \pm 0.40 \\
-1.37(-1.47,-1.27) \\
-15.24(-16.36,-14.13)\end{array}$ & $\begin{array}{l}0.118 / 0.229 \\
0.627 \\
0.433\end{array}$ \\
\hline
\end{tabular}

Note: Results (mean and 95\% confidence interval) are expressed as absolute changes and as percentage changes from baseline values.

Abbreviation: SGLT2i, sodium-glucose cotransporter type 2 inhibitor.

Table 6 Differences Between Asian versus Non-Asian Patients with Type 2 Diabetes Regarding the Effects of SGLT2is on Body Weight and Systolic Blood Pressure

\begin{tabular}{|c|c|c|c|}
\hline Parameters & $\begin{array}{l}\text { Asian Patients } \\
\text { SGLT2i versus Placebo } \\
(n=\mid 164 \text { versus } n=1088)\end{array}$ & $\begin{array}{l}\text { Non-Asian Patients } \\
\text { SGLT2i versus Placebo } \\
(n=2482 \text { versus } n=1857)\end{array}$ & $P$ values \\
\hline \multicolumn{4}{|l|}{ Body weight (kg) } \\
\hline $\begin{array}{l}\text { Baseline values (SGLT2i/placebo) } \\
\text { Delta versus baseline }(\mathrm{kg}) \\
\text { Delta versus baseline }(\%)\end{array}$ & $\begin{array}{l}71.6 \pm 4.8 / 71.2 \pm 4.5 \\
-1.60(-1.84,-1.37) \\
-2.23(-2.55,-1.90)\end{array}$ & $\begin{array}{l}883 \pm 2.5 / 87.7 \pm 1.9 \\
-1.91(-2.09,-1.73) \\
-2.16(-2.37,-1.96)\end{array}$ & $\begin{array}{l}<0.001 / 0.001 \\
0.0890 \\
0.324\end{array}$ \\
\hline \multicolumn{4}{|l|}{ Systolic blood pressure $(\mathrm{mm} \mathrm{Hg})$} \\
\hline $\begin{array}{l}\text { Baseline values (SGLT2i/placebo) } \\
\text { Delta versus baseline }(\mathrm{mm} \mathrm{Hg}) \\
\text { Delta versus baseline (\%) }\end{array}$ & $\begin{array}{l}|28.4 \pm| .6 / \mid 27.6 \pm 2.0 \\
-4.53(-5.53,-3.53) \\
-3.58(-4.96,-2.20)\end{array}$ & $\begin{array}{l}|30.2 \pm 3 .| / \mid 30.2 \pm 3.6 \\
-4.06(-4.83,-3.29) \\
-3.19(-3.8 \mid,-2.28)\end{array}$ & $\begin{array}{l}0.1574 / 0.0738 \\
0.22290 \\
0.75874\end{array}$ \\
\hline
\end{tabular}

Note: Results (mean and 95\% confidence interval) are expressed as absolute changes and as percentage changes from baseline values.

Abbreviation: SGLT2i, sodium-glucose cotransporter type 2 inhibitor.

mostly due to a reduction in body fat mass rather than to fluid loss. ${ }^{38}$ Weight loss is also accompanied by a reduction in visceral adiposity and ectopic (liver) fat. ${ }^{52,53}$ A significant reduction in SBP was observed with SGLT2i therapy, again of similar amplitude in Asian as in non-Asian patients. The amplitude of the reduction in SBP was consistent with what has been previously reported with SGLT2is,${ }^{54}$ including in East Asian patients with T2DM. ${ }^{51}$ Overall, these findings confirm previous results where comparisons of the BW and blood pressure placebo-corrected changes between Asian and non-Asian patients did not show a significant difference between groups. ${ }^{19}$

Because the range of baseline $\mathrm{HbAlc}$ was rather narrow (between $7.67 \%$ and $8.39 \%$, with only one study with baseline HbA1c of 7.19\%) in the placebo-controlled RCTs included in this meta-analysis, it was not possible to properly investigate the relation between the reduction in $\mathrm{HbAlc}$ and the baseline HbAlc levels. However, no difference in the reduction in HbA1c could be detected between Asian and non-Asian patients when studies with baseline $\mathrm{HbA} 1 \mathrm{c}<8 \%$ versus $\geq 8 \%$ were analyzed separately. By using a much larger set of data, we previously reported a significant relationship between the amplitude of the reduction in $\mathrm{HbAlc}$ and the baseline $\mathrm{HbAlc}$ levels with SGLT2is, and the slope of the relationship tended to be steeper with SGLT2is than that observed with DPP4is. ${ }^{5}$ These findings are in agreement with the results of a head-to-head RCT, which showed that incremental reductions in $\mathrm{HbAlc}$ with increasing baseline $\mathrm{HbAlc}$ are greater with the SGLT2i empagliflozin compared with the 
DPP-4i sitagliptin as monotherapy, a trial that mainly recruited non-Asian patients with T2DM. ${ }^{55}$ A stratified analysis of studies carried out in East Asian patients with T2DM also showed that patients with higher HbA1c levels at baseline achieve a greater improvement in $\mathrm{HbAlc}$ after taking SGLT2is. ${ }^{51}$

Among SGLT2is only commercialized in Asia, ipragliflozin was the most widely tested agent as added to metformin. Our results confirm a previous meta-analysis of RCTs that evaluated the effect of ipragliflozin (50-300 $\mathrm{mg} /$ day) added to metformin (alone or in combination with another glucose-lowering agent) and reported placebo-subtracted reduction in $\mathrm{HbA} 1 \mathrm{c}$ averaging $-0.66 \%$ (95\% CI $-0.79,-0.53) .{ }^{56}$ Surprisingly, no study evaluated the addition of empagliflozin in Asian patients treated with metformin monotherapy (empagliflozin was only investigated as monotherapy in one RCT in Japanese patients with diet-treated T2DM). ${ }^{57}$ There are very few head-tohead trials that compared the efficacy of two SGLT2is. None of the RCTs considered in the two present metaanalyses in Asian and non-Asian patients included a direct comparison of two SGLT2is, in addition to metformin with placebo used as control. A recent study showed that remogliflozin etabonate, a new SGLT2i commercialized in India, was noninferior to dapagliflozin when added to metformin in Indian patients with T2DM. ${ }^{58}$

Our results may be compared with findings of another meta-analysis of nine RCTs that studied the effects of an SGLT2 $\mathrm{i}$ added to metformin. It also reported higher reductions in $\mathrm{HbA} 1 \mathrm{c}(-0.50 \%, 95 \% \mathrm{CI}-0.62,-0.38), \mathrm{FPG}(-1.12$ $\mathrm{mmol} / 1,95 \% \mathrm{CI}-1.38,-0.87)$, BW $(-1.72 \mathrm{~kg}, 95 \% \mathrm{CI}$ $-2.05,-1.39)]$ and SBP $(-4.44 \mathrm{~mm} \mathrm{Hg}, 95 \% \mathrm{CI}-5.45$, $-3.43)$, versus metformin monotherapy. ${ }^{2}$ These results are closed to those reported in our study. Compared with sulfonylureas as second-line therapy in patients with T2DM inadequately controlled on metformin, SGLT2is are more effective in reducing $\mathrm{HbAlc}$ in the longer term (despite similar glycemic efficacy in a relatively short term), produce less hypoglycemic events and lead to greater reductions in BW and blood pressure. ${ }^{59}$ In comparison with DPP-4is, SGLT2is added to metformin resulted in a slightly greater reduction in $\mathrm{HbAlc}$ (overall changes versus baseline: -0.80 $\pm 0.20 \%$ versus $-0.71 \pm 0.23 \%, \mathrm{p}=0.0354),{ }^{5}$ while offering the advantage of a greater weight loss and a significant blood pressure reduction. ${ }^{6,21}$

Our analysis focused on efficacy rather than on safety. The safety profile of SGLT2is has been extensively investigated and subject to huge discussion in recent years. ${ }^{60}$
This safety profile appears to be very similar in Asian versus non-Asian patients, ${ }^{61}$ as shown in pooled analyses of trials performed with dapagliflozin, ${ }^{62}$ canagliflozin, ${ }^{63}$ and empagliflozin, ${ }^{64}$ including for empagliflozin in East Asian patients. ${ }^{65}$ The overall safety profile of SGLT2is in East Asian patients with T2DM was comparable to that classically reported in non-Asian (Caucasian) patients: ${ }^{2,60}$ SGLT2is did not increase the risk of hypoglycemia and urinary tract infections, but did increase the risk of mycotic genital tract infections. ${ }^{51}$

The role of SGLT2is in the management of T2DM among East Asians is an interesting area of research, given that East Asians have been proven to be uniquely different from Caucasians. ${ }^{66}$ The efficacy and safety of SGLT2is in East Asians with T2DM were investigated in a meta-analysis of 33 RCTs that randomized 8496 patients treated with SGLT2is as either monotherapy or add-on therapy compared with placebo or other antihyperglycemic medications. ${ }^{51}$ Compared with the control group, the use of SGLT2is improved HbA1c (WMD -0.73\%; 95\% CI -0.84, -0.61), lowered FPG (WMD -1.58 mmol/1; 95\% CI -1.83, -1.34) and reduced body weight (WMD $-1.73 \mathrm{~kg} ; 95 \% \mathrm{CI}-2.28$, -1.17). These results are closed to those of our study. Because SGLT2is are the only oral glucose-lowering agents that have been shown to reduce BW and visceral adiposity, they represent an evidence-based therapeutic option for the management of overweight/obese patients with T2DM. ${ }^{53}$

The strength of this study is that it analyzed a large set of homogeneous RCTs, all comparing the effects of an SGLT2i when added to metformin monotherapy in Asian versus non-Asian patients with T2DM. It provides consistent positive results concerning four main surrogate metabolic and clinical endpoints, ie $\mathrm{HbA1c}$, FPG, BW and SBP. A first limitation is that our analysis was based on indirect comparison in the absence of available direct comparison in the literature. One large RCT recruited about half of the patients as Asian and about half as non-Asian, but did not give separate results for the two ethnic groups. ${ }^{47}$ A second limitation was the rather low number of patients included in some RCTs, which attenuates the statistical power of these studies. In addition, there was a significant between-study heterogeneity regarding improvement in glucose control (HbAlc and FPG). A third limitation is that the non-Asian population may be heterogeneous as besides a majority of Caucasians, it may also comprise Hispanics or Afroamericans. However, as no separate results were reported in the different studies, it was not possible to perform a comparison strictly focusing on Caucasians. A final 
limitation is the rather narrow range of $\mathrm{HbAlc}$ investigated as a majority of RCTs included T2DM patients with mean baseline HbA1c levels comprised between $7.70 \%$ and $8.40 \%$. Thus, our analysis concerns patients with moderately poor glycemic control and cannot be extrapolated to patients with more severely uncontrolled diabetes. Nevertheless, this HbAlc range corresponds to that commonly seen in a large proportion of T2DM patients whose therapy should be intensified after failure of metformin monotherapy in routine clinical practice.

\section{Conclusion}

In patients with T2DM insufficiently controlled with metformin monotherapy, the addition of an SGLT2i versus placebo was associated with consistent reductions in HbA1c, FPG, BW and SBP. No significant differences could be detected between Asian and non-Asian patients. These results confirm that SGLT2is exert their positive effects on several surrogate metabolic and clinical endpoints, independently of ethnicity and the underlying phenotype and pathophysiology of T2DM.

\section{Acknowledgments}

The author thanks Monique Marchand for her valuable help in the literature search and the subsequent statistical analyses

\section{Disclosure}

No sources of funding were used to assist in the preparation of this manuscript. No conflicts of interest are directly relevant to the content of this manuscript.

A.J. Scheen has received lecturer/scientific advisor/clinical investigator fees from AstraZeneca, Boehringer Ingelheim, Eli Lilly, Janssen, Merck Sharp \& Dohme, Novartis, NovoNordisk, Sanofi-Aventis and Servier. He worked as a clinical investigator in EMPA-REG OUTCOME, CANVAS-R and DECLARE-TIMI 58 cardiovascular outcome trials that evaluated SGLT2is.

\section{References}

1. Buse JB, Wexler DJ, Tsapas A, et al. 2019 Update to: management of hyperglycemia in type 2 diabetes, 2018. A consensus report by the American Diabetes Association (ADA) and the European Association for the Study of Diabetes (EASD). Diabetes Care. 2020;43 (2):487-493. doi:10.2337/dci19-0066

2. Jingfan Z, Ling L, Cong L, Ping L, Yu C. Efficacy and safety of sodium-glucose cotransporter- 2 inhibitors in type 2 diabetes mellitus with inadequate glycemic control on metformin: a meta-analysis. Arch Endocrinol Metab. 2019;63(5):478-486. doi:10.20945/23593997000000146
3. Scheen AJ. Sodium-glucose co-transporter type 2 inhibitors for the treatment of type 2 diabetes mellitus. Nature Rev Endocrinol. 2020;in press.

4. Liu Y, Hong T. Combination therapy of dipeptidyl peptidase-4 inhibitors and metformin in type 2 diabetes: rationale and evidence. Diabetes Obes Metab. 2014;16(2):111-117. doi:10.1111/dom.12128

5. Scheen AJ. Reduction in HbA1c with SGLT2 inhibitors vs. DPP-4 inhibitors as add-ons to metformin monotherapy according to baseline HbAlc: a systematic review of randomized controlled trials. Diabetes Metab. 2020;46(3):186-196. doi:10.1016/j.diabet.2020.01.002

6. Scheen AJ. Cardiovascular effects of new oral glucose-lowering agents: DPP-4 and SGLT-2 inhibitors. Circ Res. 2018;122 (10):1439-1459. doi:10.1161/CIRCRESAHA.117.311588

7. Rhee EJ. Diabetes in Asians. Endocrinol Metab (Seoul). 2015;30 (3):263-269. doi:10.3803/EnM.2015.30.3.263

8. Yang W, Weng J. Early therapy for type 2 diabetes in China. Lancet Diabetes Endocrinol. 2014;2(12):992-1002. doi:10.1016/S22138587(14)70136-6

9. Cai XL, Ji LN. Treatment response between Asian and non-Asian patients with type 2 diabetes: is there any similarity or difference? Chin Med $J$ (Engl). 2019;132(1):1-3. doi:10.1097/CM9.0000 000000000012

10. Kim YG, Hahn S, Oh TJ, Park KS, Cho YM. Differences in the HbA1c-lowering efficacy of glucagon-like peptide-1 analogues between Asians and non-Asians: a systematic review and meta-analysis. Diabetes Obes Metab. 2014;16(10):900-909. doi:10.1111/dom.12293

11. Scheen AJ. Oral semaglutide in Japanese versus non-Japanese patients with type 2 diabetes. Lancet Diabetes Endocrinol. 2020;8 (5):350-352. doi:10.1016/S2213-8587(20)30079-6

12. Kim YG, Hahn S, Oh TJ, Kwak SH, Park KS, Cho YM. Differences in the glucose-lowering efficacy of dipeptidyl peptidase-4 inhibitors between Asians and non-Asians: a systematic review and meta-analysis. Diabetologia. 2013;56(4):696-708. doi:10.1007/ s00125-012-2827-3

13. Cai X, Han X, Luo Y, Ji L. Efficacy of dipeptidyl-peptidase-4 inhibitors and impact on $\beta$-cell function in Asian and Caucasian type 2 diabetes mellitus patients: a meta-analysis. $J$ Diabetes. 2015;7(3):347-359. doi:10.1111/1753-0407.12196

14. Zhou Y, Geng Z, Wang X, Huang Y, Shen L, Wang Y. Meta-analysis on the efficacy and safety of SGLT2 inhibitors and incretin based agents combination therapy vs. SGLT2i alone or add-on to metformin in type 2 diabetes. Diabetes Metab Res Rev. 2020;36(2):e3223. doi:10.1002/dmrr.3223

15. Abdul-Ghani MA, Norton L, Defronzo RA. Role of sodium-glucose cotransporter 2 (SGLT 2) inhibitors in the treatment of type 2 diabetes. Endocr Rev. 2011;32(4):515-531. doi:10.1210/er.2010-0029

16. Scheen AJ. Pharmacodynamics, efficacy and safety of sodium-glucose co-transporter type 2 (SGLT2) inhibitors for the treatment of type 2 diabetes mellitus. Drugs. 2015;75(1):33-59. doi:10.1007/s40265-014-0337-y

17. Scheen AJ, Paquot N. Metabolic effects of SGLT2 inhibitors beyond increased glucosuria: a review of clinical evidence. Diabetes Metab. 2014;40(Suppl):S4-S11. doi:10.1016/S1262-3636(14)72689-8

18. Kaneto H, Obata A, Kimura T, et al. Beneficial effects of sodiumglucose cotransporter 2 inhibitors for preservation of pancreatic $\beta$ cell function and reduction of insulin resistance. J Diabetes. 2017;9 (3):219-225. doi:10.1111/1753-0407.12494

19. Cai X, Gao X, Yang W, et al. No disparity of the efficacy and all-cause mortality between Asian and non-Asian type 2 diabetes patients with sodium-glucose cotransporter 2 inhibitors treatment: a meta-analysis. J Diabetes Investig. 2018;9(4):850-861. doi:10.1111/jdi.12760

20. van Baar MJB, van Ruiten CC, Muskiet MHA, van Bloemendaal L, IJzerman RG, van Raalte DH. SGLT2 inhibitors in combination therapy: from mechanisms to clinical considerations in type 2 diabetes management. Diabetes Care. 2018;41(8):1543-1556. doi: $10.2337 / \mathrm{dc} 18-0588$ 
21. Scheen AJ. SGLT2 versus DPP4 inhibitors for type 2 diabetes. Lancet Diabetes Endocrinol. 2013;1(3):168-170. doi:10.1016/ S2213-8587(13)70095-0

22. Goldenberg RM. Choosing dipeptidyl peptidase-4 inhibitors, sodium-glucose cotransporter-2 inhibitors, or both, as add-ons to metformin: patient baseline characteristics are crucial. Clin Ther. 2017;39(12):2438-2447. doi:10.1016/j.clinthera.2017.10.016

23. Moon MK, Hur KY, Ko SH, et al. Committee of clinical practice guidelines of the Korean diabetes, association. combination therapy of oral hypoglycemic agents in patients with type 2 diabetes mellitus. Korean J Intern Med. 2017;32(6):974-983. doi:10.3904/kjim.2017.354

24. Deerochanawong C, Chan SP, Matawaran BJ, et al. Use of sodium-glucose co-transporter-2 inhibitors in patients with type 2 diabetes mellitus and multiple cardiovascular risk factors: an Asian perspective and expert recommendations. Diabetes Obes Metab. 2019;21(11):2354-2367. doi:10.1111/dom.13819

25. Kaku K, Lee J, Mattheus M, et al. Empagliflozin and cardiovascular outcomes in asian patients with type 2 diabetes and established cardiovascular disease- results from EMPA-REG OUTCOME ${ }^{\circledR}$. Circ J. 2017;81(2):227-234. doi:10.1253/circj.CJ-16-1148

26. Wang Z, Sun J, Han R, et al. Efficacy and safety of sodium-glucose cotransporter- 2 inhibitors versus dipeptidyl peptidase- 4 inhibitors as monotherapy or add-on to metformin in patients with type 2 diabetes mellitus: a systematic review and meta-analysis. Diabetes Obes Metab. 2018;20(1):113-120. doi:10.1111/dom.13047

27. Mishriky BM, Tanenberg RJ, Sewell KA, Cummings DM. Comparing SGLT-2 inhibitors to DPP-4 inhibitors as an add-on therapy to metformin in patients with type 2 diabetes: a systematic review and meta-analysis. Diabetes Metab. 2018;44(2):112-120. doi:10.1016/j.diabet.2018.01.017

28. Ji L, Han P, Liu Y, et al. Canagliflozin in Asian patients with type 2 diabetes on metformin alone or metformin in combination with sulphonylurea. Diabetes Obes Metab. 2015;17(1):23-31. doi:10.1111/dom.12385

29. Yang W, Han P, Min KW, et al. Efficacy and safety of dapagliflozin in Asian patients with type 2 diabetes after metformin failure: a randomized controlled trial. J Diabetes. 2016;8(6):796-808. doi:10.1111/1753-0407.12357

30. Ji L, Liu Y, Miao H, et al. Safety and efficacy of ertugliflozin in Asian patients with type 2 diabetes mellitus inadequately controlled with metformin monotherapy: VERTIS Asia. Diabetes Obes Metab. 2019;21(6):1474-1482. doi:10.1111/dom.13681

31. Kashiwagi A, Kazuta K, Goto K, Yoshida S, Ueyama E, Utsuno A. Ipragliflozin in combination with metformin for the treatment of Japanese patients with type 2 diabetes: ILLUMINATE, a randomized, double-blind, placebo-controlled study. Diabetes Obes Metab. 2015;17(3):304-308. doi:10.1111/dom.12331

32. Lu CH, Min KW, Chuang LM, Kokubo S, Yoshida S, Cha BS. Efficacy, safety, and tolerability of ipragliflozin in Asian patients with type 2 diabetes mellitus and inadequate glycemic control with metformin: results of a Phase 3 randomized, placebo-controlled, double-blind, multicenter trial. J Diabetes Investig. 2016;7 (3):366-373. doi:10.1111/jdi.12422

33. Min KW, Ku BJ, Lee JH, et al. Addition of ipragliflozin to metformin treatment in Korean patients with type 2 diabetes mellitus: subgroup analysis of a phase 3 trial. Diabetes Metab J. 2017;41(2):135-145. doi:10.4093/dmj.2017.41.2.135

34. Ikeda S, Takano Y, Cynshi O, et al. A novel and selective sodium-glucose cotransporter-2 inhibitor, tofogliflozin, improves glycaemic control and lowers body weight in patients with type 2 diabetes mellitus. Diabetes Obes Metab. 2015;17(10):984-993. doi:10.1111/dom.12538

35. Rosenstock J, Aggarwal N, Polidori D, et al. Dose-ranging effects of canagliflozin, a sodium-glucose cotransporter 2 inhibitor, as add-on to metformin in subjects with type 2 diabetes. Diabetes Care. 2012;35(6):1232-1238. doi:10.2337/dc11-1926
36. Lavalle-Gonzalez FJ, Januszewicz A, Davidson J, et al. Efficacy and safety of canagliflozin compared with placebo and sitagliptin in patients with type 2 diabetes on background metformin monotherapy: a randomised trial. Diabetologia. 2013;56(12):2582-2592. doi:10.1007/s00125-013-3039-1

37. Bailey CJ, Gross JL, Pieters A, Bastien A, List JF. Effect of dapagliflozin in patients with type 2 diabetes who have inadequate glycaemic control with metformin: a randomised, double-blind, placebo-controlled trial. Lancet. $\quad$ 2010;375(9733):2223-2233. doi:10.1016/S0140-6736(10) 60407-2

38. Bolinder J, Ljunggren O, Kullberg J, et al. Effects of dapagliflozin on body weight, total fat mass, and regional adipose tissue distribution in patients with type 2 diabetes mellitus with inadequate glycemic control on metformin. J Clin Endocrinol Metab. 2012;97 (3):1020-1031. doi:10.1210/jc.2011-2260

39. Ljunggren O, Bolinder J, Johansson L, et al. Dapagliflozin has no effect on markers of bone formation and resorption or bone mineral density in patients with inadequately controlled type 2 diabetes mellitus on metformin. Diabetes Obes Metab. 2012;14(11):990-999. doi:10.1111/j.1463-1326.2012.01630.x

40. Schumm-Draeger PM, Burgess L, Koranyi L, Hruba V, HamerMaansson JE, de Bruin TW. Twice-daily dapagliflozin co-administered with metformin in type 2 diabetes: a 16 -week randomized, placebo-controlled clinical trial. Diabetes Obes Metab. 2015;17(1):42-51. doi:10.1111/dom.12387

41. Rosenstock J, Seman LJ, Jelaska A, et al. Efficacy and safety of empagliflozin, a sodium glucose cotransporter 2 (SGLT2) inhibitor, as add-on to metformin in type 2 diabetes with mild hyperglycaemia. Diabetes Obes Metab. 2013;15(12):1154-1160. doi:10.1111/dom.12185

42. Ross S, Thamer C, Cescutti J, Meinicke T, Woerle HJ, Broedl UC. Efficacy and safety of empagliflozin twice daily versus once daily in patients with type 2 diabetes inadequately controlled on metformin: a 16-week, randomized, placebo-controlled trial. Diabetes Obes Metab. 2015;17(7):699-702. doi:10.1111/dom.12469

43. Rosenstock J, Frias J, Pall D, et al. Effect of ertugliflozin on glucose control, body weight, blood pressure and bone density in type 2 diabetes mellitus inadequately controlled on metformin monotherapy (VERTIS MET). Diabetes Obes Metab. 2018;20(3):520-529. doi:10.1111/dom.13103

44. Wilding JP, Ferrannini E, Fonseca VA, Wilpshaar W, Dhanjal P, Houzer A. Efficacy and safety of ipragliflozin in patients with type 2 diabetes inadequately controlled on metformin: a dose-finding study. Diabetes Obes Metab. 2013;15(5):403-409. doi:10.1111/dom.12038

45. Shestakova MV, Wilding JPH, Wilpshaar W, Tretter R, Orlova VL, Verbovoy AF. A phase 3 randomized placebo-controlled trial to assess the efficacy and safety of ipragliflozin as an add-on therapy to metformin in Russian patients with inadequately controlled type 2 diabetes mellitus. Diabetes Res Clin Pract. 2018;146:240-250. doi:10.1016/j.diabres.2018.10.018

46. Amin NB, Wang X, Jain SM, Lee DS, Nucci G, Rusnak JM. Doseranging efficacy and safety study of ertugliflozin, a sodium-glucose co-transporter 2 inhibitor, in patients with type 2 diabetes on a background of metformin. Diabetes Obes Metab. 2015;17 (6):591-598. doi:10.1111/dom.12460

47. Haring HU, Merker L, Seewaldt-Becker E, et al. Empagliflozin as add-on to metformin in patients with type 2 diabetes: a 24-week, randomized, double-blind, placebo-controlled trial. Diabetes Care. 2014;37(6):1650-1659. doi:10.2337/dc13-2105

48. Scheen AJ. Pharmacokinetic/pharmacodynamic properties and clinical use of SGLT2 inhibitors in non-Asian and Asian patients with type 2 diabetes and chronic kidney disease. Clin Pharmacokinet. 2020. doi:10.1007/s40262-40020-00885-z

49. Drucker DJ, Nauck MA. The incretin system: glucagon-like peptide-1 receptor agonists and dipeptidyl peptidase- 4 inhibitors in type 2 diabetes. Lancet. 2006;368(9548):1696-1705. doi:10.1016/ S0140-6736(06)69705-5 
50. Cai X, Yang W, Gao X, et al. The association between the dosage of SGLT2 inhibitor and weight reduction in type 2 diabetes patients: a meta-analysis. Obesity. 2018;26(1):70-80. doi:10.1002/oby.22066

51. Yang L, Zhang L, He H, Zhang M, An Z. Efficacy and safety of sodium-glucose cotransporter 2 inhibitors in East Asians with type 2 diabetes: a systematic review and meta-analysis. Diabetes Ther. 2019;10(5):1921-1934. doi:10.1007/s13300-019-0674-7

52. Scheen AJ. Beneficial effects of SGLT2 inhibitors on fatty liver in type 2 diabetes: a common comorbidity associated with severe complications. Diabetes Metab. 2019;45(3):213-223. doi:10.1016/j. diabet.2019.01.008

53. Sheu WHH, Chan SP, Matawaran BJ, et al. Use of SGLT-2 inhibitors in patients with type 2 diabetes mellitus and abdominal obesity: an Asian perspective and expert recommendations. Diabetes Metab J. 2020;44(1):11-32. doi:10.4093/dmj.2019.0208

54. Mazidi M, Rezaie P, Gao HK, Kengne AP. Effect of sodium-glucose cotransport-2 inhibitors on blood pressure in people with type 2 diabetes mellitus: a systematic review and meta-analysis of 43 randomized control trials with 22528 patients. J Am Heart Assoc. 2017;6(6):e004007. doi:10.1161/JAHA.116.004007

55. DeFronzo RA, Ferrannini E, Schernthaner G, et al. Slope of change in $\mathrm{HbA}$ 1c from baseline with empagliflozin compared with sitagliptin or glimepiride in patients with type 2 diabetes. Endocrinol Diabetes Metab. 2018;1(2):e00016. doi:10.1002/edm2.16

56. Chen W, Li P, Wang G, Chen Y, Wang B, Chen M. Efficacy and safety of ipragliflozin as add-on to metformin for type 2 diabetes: a meta-analysis of double-blind randomized controlled trials. Postgrad Med. 2019;131(8):578-588. doi:10.1080/00325481.2019.1655381

57. Kadowaki T, Haneda M, Inagaki N, et al. Efficacy and safety of empagliflozin monotherapy for 52 weeks in Japanese patients with type 2 diabetes: a randomized, double-blind, parallel-group study. Adv Ther. 2015;32(4):306-318. doi:10.1007/s12325-015-0198-0

58. Dharmalingam M, Aravind SR, Thacker H, et al. Efficacy and safety of remogliflozin etabonate, a new sodium glucose co-transporter-2 inhibitor, in patients with type 2 diabetes mellitus: a 24-week, randomized, double-blind, active-controlled trial. Drugs. 2020;80 (6):587-600. doi:10.1007/s40265-020-01285-0
59. Chen Z, Li G. Sodium-glucose co-transporter 2 inhibitors compared with sulfonylureas in patients with type 2 diabetes inadequately controlled on metformin: a meta-analysis of randomized controlled trials. Clin Drug Investig. 2019;39(6):521-531. doi:10.1007/s40261019-00781-w

60. Scheen AJ. An update on the safety of SGLT2 inhibitors. Expert Opin Drug Safety. 2019;18(4):295-311. doi:10.1080/14740338.2019.1602116

61. Fujita Y, Inagaki N. An update on efficacy and safety of SGLT2 inhibitors in Asians and non-Asians. J Diabetes Investig. 2019;10 (6):1408-1410. doi:10.1111/jdi.13150

62. Yang W, Ji L, Zhou Z, Cain VA, Johnsson KM, Sjostrom CD. Efficacy and safety of dapagliflozin in Asian patients: a pooled analysis. J Diabetes. 2017;9(8):787-799. doi:10.1111/1753-0407.12484

63. Inagaki N, Harashima SI, Iijima H. Canagliflozin for the treatment of type 2 diabetes: a comparison between Japanese and non-Japanese patients. Expert Opin Pharmacother. 2018;19(8):895-908. doi:10.1080/14656566.2018.1473378

64. Zhang YJ, Han SL, Sun XF, et al. Efficacy and safety of empagliflozin for type 2 diabetes mellitus: meta-analysis of randomized controlled trials. Medicine (Baltimore). 2018;97(43):e12843. doi:10.1097/MD.0000000000012843

65. Yabe D, Yasui A, Ji L, et al. Safety and tolerability of empagliflozin in East Asian patients with type 2 diabetes: pooled analysis of Phase I-III clinical trials. J Diabetes Investig. 2019;10(2):418-428. doi:10.1111/jdi.12910

66. Lim LL, Tan ATB, Moses K, Rajadhyaksha V, Chan SP. Place of sodium-glucose cotransporter-2 inhibitors in East Asian subjects with type 2 diabetes mellitus: insights into the management of Asian phenotype. J Diabetes Complications. 2017;31(2):494-503. doi:10. 1016/j.jdiacomp.2016.10.008

Diabetes, Metabolic Syndrome and Obesity: Targets and Therapy

Dovepress

\section{Publish your work in this journal}

Diabetes, Metabolic Syndrome and Obesity: Targets and Therapy is an international, peer-reviewed open-access journal committed to the rapid publication of the latest laboratory and clinical findings in the fields of diabetes, metabolic syndrome and obesity research. Original research, review, case reports, hypothesis formation, expert opinion and commentaries are all considered for publication. The manuscript management system is completely online and includes a very quick and fair peer-review system, which is all easy to use. Visit http://www.dovepress.com/testimonials.php to read real quotes from published authors. 